\title{
ADAPTIVE SPEED LIMIT FOR LAST MILE VEHICLES ON PUBLIC WALKWAYS
}

\author{
LUTZ KASTENBAUER, RUBEN KÖNIG, JULIA LAY, LUKAS WIZEMANN, \\ FABIAN SCHMIEL \& OLIVER ZIRN \\ Automotive Faculty, Esslingen University of Applied Sciences, Esslingen, Germany
}

\begin{abstract}
Foldable ultralight electric vehicles (E-ULV) are a promising key component for future sustainable traffic chains for urban regions with mountainous topography. While E-Bikes are prohibited in metropolitan public transport during rush-hours, foldable E-ULV are a real innovation for the "last mile" to the destination. This paper presents electric drive add-on kits for foldable scooters that can be used on public walkways, train stations and subway platforms. The key innovation of these very lightweight and powerful foldable scooters is the adaptive speed limitation based on an ultrasonic sensor that limits the maximum velocity on crowded walkways and permits a faster movement up to jogging velocity if the walkway is obstacle-free. The E-ULV has been tested legally in small fleets on public walkways in Stuttgart and Esslingen by special permission of the Ministry for Traffic and Infrastructure, Stuttgart. E-ULV for the "last mile" will reduce car kilometers and transfer them to the public transport system. Furthermore, parking lot search traffic can be avoided in crowded city centres with a E-ULV in the car trunk
\end{abstract}

Keywords: ultralight vehicles, E-Mobility, public transport.

\section{INTRODUCTION}

Foldable scooters and bicycles are well known for decades. In flat metropolitan regions like Berlin, Hamburg or Cologne a light foldable vehicle is often used instead of walking or using a bicycle between the apartment and working place, tramway station or train station [1]. In mountainous metropolitan regions like Zürich or Stuttgart, vehicles without additional power assistance are exhausting on longer climbs. Using foldable scooters long downhill distances are a real challenge. The typical rear wheel friction brake is best to be for used for emergency stops as well as for short slopes. On longer slopes the friction heat leads to a melted shoe sole. Although several electrical power assisted folding bikes (so called foldingPEDELEC's) are available on the marked, these bikes are quite heavy ( $>18 \mathrm{~kg})$, extremely expensive or of questionable quality. Moreover, all premium folding bike manufacturers have withdrawn their electrified versions in the last few years. Electrified folding scooters are available from Asian manufacturers (cheap and heavy) and latterly from Switzerland (lightweight and expensive) - all together much too fast (up to $25 \mathrm{~km} / \mathrm{h}$ ) and with no legal admission for middle European public roads or walkways.

The Esslingen and Stuttgart Universities of Applied Sciences research cooperation "TrottiElec" developed an electric drive add-on kit for a lightweight, electrical power assisted folding bike for public roads [2], as well as for slow folding scooters with high gradability on public walkways (see Fig. 1). Furthermore, the research cooperation obtained the support of the Ministry for Traffic and Infrastructure Baden-Württemberg (MVI-BW) for a temporary legal test fleet. The objectives of this fleet experiment are the scientific sustainability and acceptance proof for E-ULV to initiate a suitable vehicle category and suitable product developments in middle Europe.

\section{ELECTRICAL POWER ASSISTED FOLDING SCOOTERS}

Folding scooters without power assistance are considered as toys and are tolerated by the German traffic authorities for use on public walkways. Their usage on public streets however 


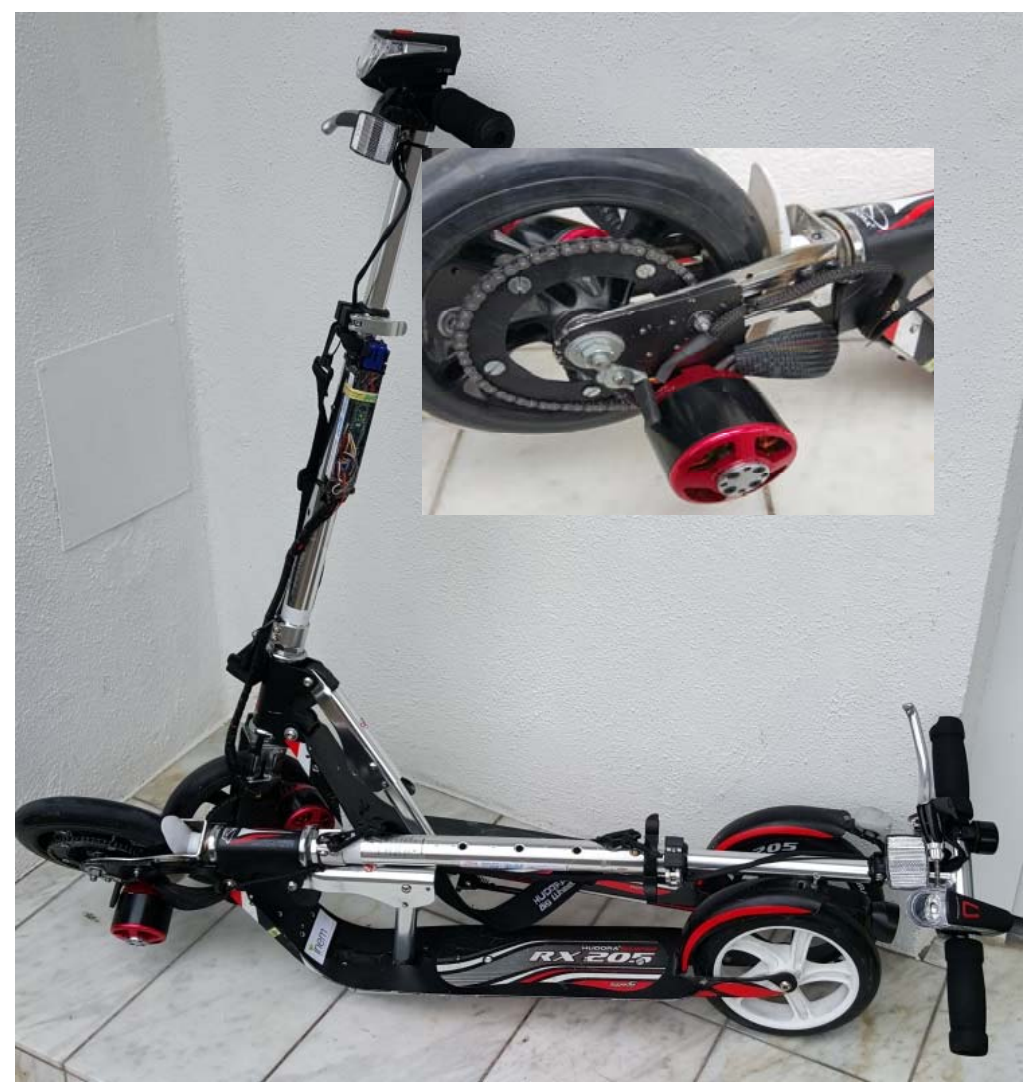

Figure 1: Electrified Scooters (folded/unfolded), BLDC-Outrunner chain drive.

is prohibited. Electrified scooters are power-driven vehicles and thus not allowed on walkways except for aids for handicapped people (third wheel, seat and handicapped ID required). Electrified scooters for public street usage require a type approval as well as a vehicle category. At the moment, the type approval is only achievable for bicycle-like scooters (heavy and large). A suitable vehicle category does not exist yet, although there are efforts on European Union level to introduce a "Personal Light Electric Vehicle (PLEV)"category for the street [3].

However, an electrified scooter for closed public transportation chains should be usable on walkways or train stations.

Fundamental discussions with the sustainable mobility department of the MVI-BW result in the following preconditions for a time-limited admission of a test fleet in Stuttgart and Esslingen:

- $6 \mathrm{~km} / \mathrm{h}$ maximum velocity for electrical power assistance

- Tamper-proof drive chain

- Kicking assistance (comparable to the pedaling assistance of EPAC's)

- Dead-man-switch (drive stops, in case of loss of vehicle or if the driver is hamstrung) 
- Friction brake and recuperation brake

- Vehicle identification number (FIN)

- Deviant from $\$ 2$ StVO public walkway has to be used

- No admission or type approval required

- No driving license or minimum age required

- Width limitation to $<0.7 \mathrm{~m}$

- Briefing of probands prior to fleet test participation

Fig. 2 shows the vehicle diagram of the add-on kit that fulfils the above-mentioned preconditions [4]. The main components are described in Table 1. The BLDC-Outrunner motor and the BLDC-power electronics are controlled by a microcontroller. The user input (thumb switch and brake lever) is transposed into the vehicle characteristic diagram shown in Fig. 2. Velocity and acceleration are measured by a hall switch in the stray magnetic field of the outrunner. The software kick sensor enables the electric assistance if a minimum acceleration is detected and holds this 'enabling status' for several seconds. The start-up lockup requires a certain minimum velocity to prevent misuse or mechanical injuries at the driven front wheel. All drive and brake set points are low-pass filtered for smooth handling and braking performance.

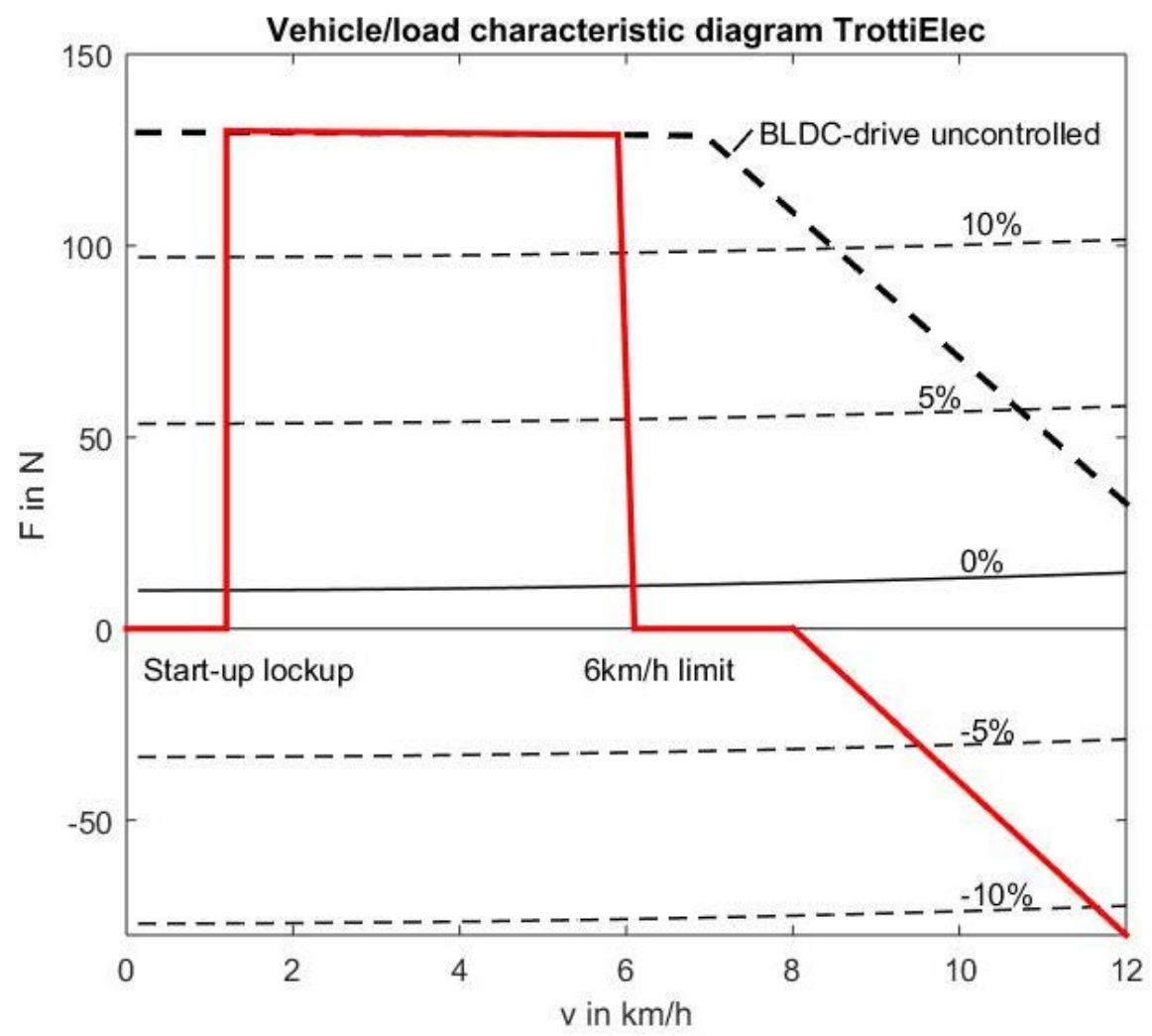

Figure 2: Vehicle and load characteristic diagram with $6 \mathrm{~km} / \mathrm{h}$ speed limitation. 
Table 1: TrottiElec add-on kit components.

\begin{tabular}{|l|l|}
\hline BLDC-outrunner & Wild FH6365 with $46 \mathrm{mVs} / \mathrm{rad}$ \\
\hline Peak Power & $250 \mathrm{~W}$ \\
\hline Rated Power & $150 \mathrm{~W}$ \\
\hline Battery & $\begin{array}{l}\text { 2P3S LiNano LiFePO } 4.2 \mathrm{Ah} \rightarrow \text { about } \\
40 \mathrm{Wh}\end{array}$ \\
\hline Chain gear & $5.7: 1 \mathrm{DIN} 04 \mathrm{~B} 1$ \\
\hline Additional mass & about $1.5 \mathrm{~kg}$ \\
\hline Recuperative braking & $\begin{array}{l}\text { about } 10 \mathrm{~A} \text { at } 6 \mathrm{~km} / \mathrm{h} \rightarrow 0.5 \mathrm{~m} / \mathrm{s} \\
\text { deceleration }\end{array}$ \\
\hline Distance sensor & $\begin{array}{l}\text { XL-MaxSonar-EZ/AE0 } \rightarrow \text { about } 7 \mathrm{~m} \\
\text { range }\end{array}$ \\
\hline Interface output format & Analog voltage output \\
\hline
\end{tabular}

The battery is protected against overvoltage in case of long recuperative braking. A cutoff relay turns the TrottiElec down if it has not been used for more than five minutes to avoid deep discharge by the microcontroller and the BLDC-controller standby current.

The first prototypes have been tested on the university campuses and halls for several months and turned out to be very robust and reliable. The smooth running outrunner with small iron losses below $10 \mathrm{~km} / \mathrm{h}$ and the single-stage chain gear make the scooter kickable even without electrical assistance - nevertheless, the battery has to be connected to protect the BLDCcontroller input capacitors from overvoltage.

The Technical Supervisory Association (TÜV-Süd, Munich/Pforzheim) inspected the first prototypes and confirmed their conformity to the MVI-BW obligations (certificate no. 6230462318). Based on this certificate, the local traffic authorities in Esslingen and Stuttgart support a 2-year fleet experiment on public walkways.

\section{ADAPTIVE SPEED LIMITATION}

The first fleet tests in Stuttgart and Esslingen in October 2016 turned out that the acceptance and the benefit of the TrottiElecs with $6 \mathrm{~km} / \mathrm{h}$ maximum electric power assistance is not satisfying. On crowded walkways, the $6 \mathrm{~km} / \mathrm{h}$ limit is necessary to avoid dangerous speed differences to other pedestrians, accidents and loss of acceptance by pedestrians. On free walkways, the scooters can be operated with jogging velocity safely.

Therefore, the ASL-Assistant, shown in Fig. 3, was developed. With the aid of an ultrasonic distance sensor it is possible to detect obstacles like pedestrians or objects in a defined range. If the walkway isn't obstacle-free, the scooter's motor changes to idle run. As consequence, the vehicle reduces speed and avoids the danger of collisions according to electric acceleration on crowded or narrow walkways. Thus, the scooter passes the obstacle without electric support. In this case, the electric scooter acts like a non-motorized scooter. That means the motor doesn't brake by itself when detecting an obstacle but stops the electrical assistance until the obstacle is passed. When the driver wants to come to a standstill he has to apply the brake. Braking does not automatically protect the driver against unexpected braking manoeuvres. In comparison, the driver of a non-motorized scooter also gets faster by kicking the scooter. If he wants to stop because of an obstacle on the walkway he must apply the brake as well. 


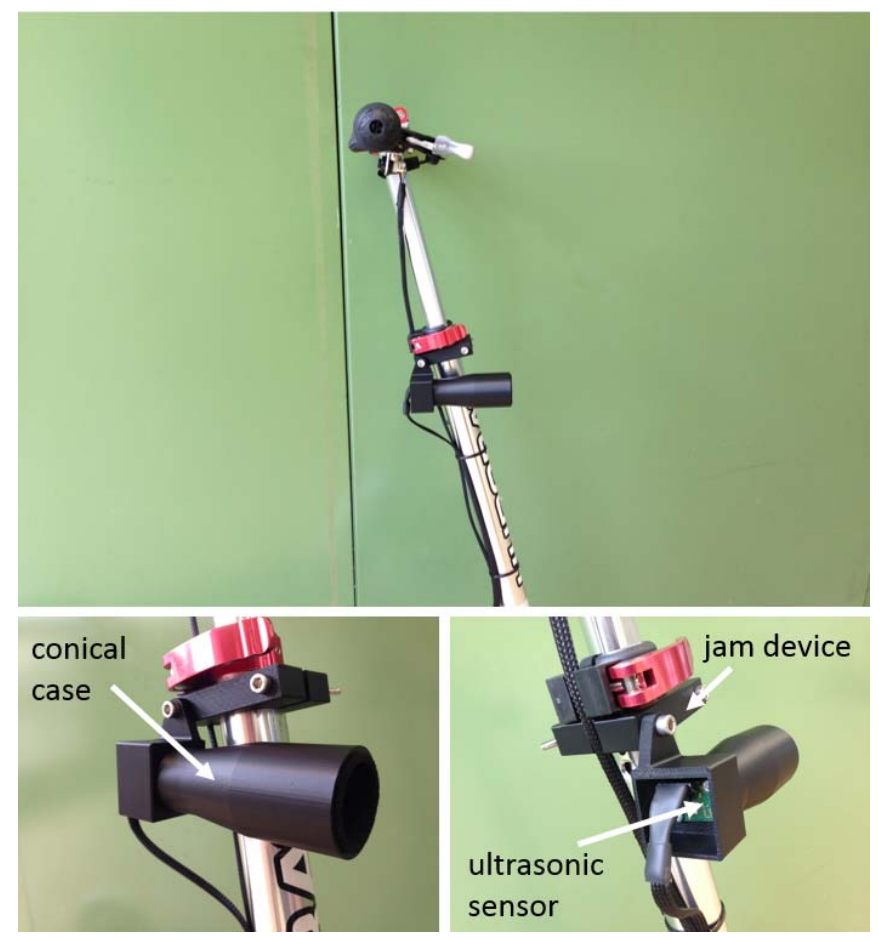

Figure 3: Ultrasonic sensor fixed to the steering bar.

The configuration of scooter and ultrasonic sensor is shown in Fig. 3. The ultrasonic sensor is located at the center of the conical case. The conical case has a length of approx. 11 $\mathrm{cm}$ and its inside is lined with felt to avoid reflection of the case. The sensor and its case are placed at the steering bar with the aid of a jam device at a height of $73 \mathrm{~cm}$. At this height, it's possible to detect the thighs of an adult as well as toddlers. A lower height would increase the floor reflection noise.

For using the ASL-system in the best possible way, it's necessary to determine sensor and control requirements. The most important requirement for the distance sensor is the detection of objects as well as pedestrians in a distance of at least $4 \mathrm{~m}$ to provide the reaction time necessary for regulating and power removing. To fulfil these functions the reaction time should be as fast as possible. Furthermore, the laterally width-range of the detection area has to be small to allow passing immobile objects with jogging velocity. In addition, costs and efforts for the sensor commission should be compatible to the project capacity.

For distance detection, usually sensors based on radar, video, laser or ultrasonic are applied. Applying video or laser equipment is expensive while ultrasonic and radar sensors are cheaper and less complex regarding the data evaluation. Radar measures distances and velocities of obstacles, but works with high frequencies, which are much higher than the calculating frequency of the microcontroller. Therefore, frequency modulation would be necessary. Finally, the best sensor for detecting small distances is the ultrasonic sensor which meets our requirements in the best way. Ultrasonic sensors have a limited range of a few meters, are comparably cheap and are commonly used for automotive applications like parking assistance. 


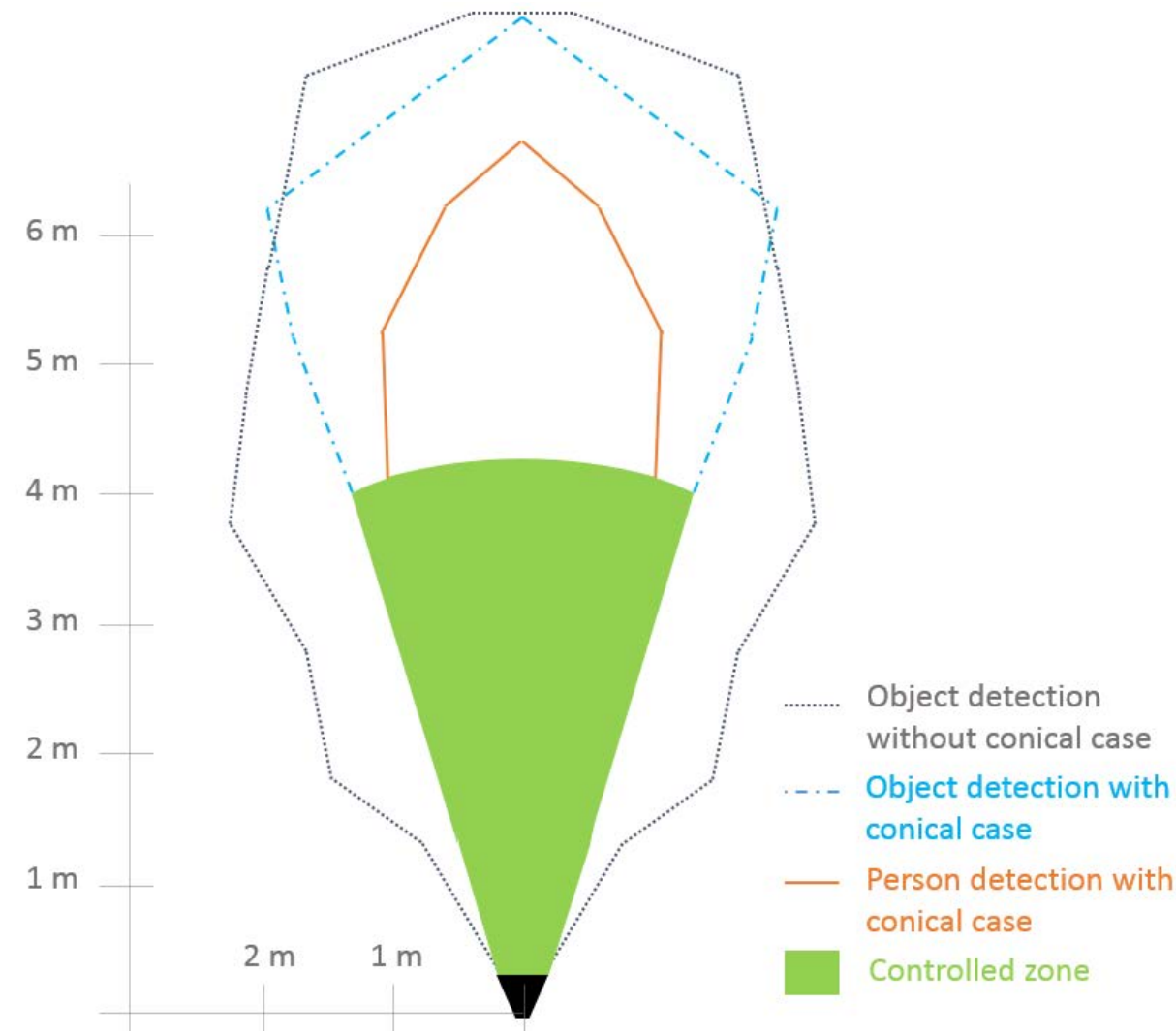

Figure 4: Detection zones of the ultrasonic sensor with and without conical case.

The selected sensor has a maximum length range of $7 \mathrm{~m}$ and a lateral range of $3 \mathrm{~m}$. Therefore, a conical case installed on the sensor is necessary to reduce the detection zone.

Fig. 4 shows the different detection zones of the ultrasonic sensor with and without conical case. A conical case installed on the distance sensor has significant influence on the laterally width of the detection zone. In Fig. 4 the ranges of the object detection and person detection are distinguished. The grey border-line indicates the limit of object detection without any adapted case. The laterally width of this detection zone is more than $2 \mathrm{~m}$ and thus driving in a parallel manner to house walls would be difficult. The blue and the brown lines show slimmer areas of detection due to the conical case. The controlled zone is described by the green area. It can be seen, that the maximal lateral controlled distance to an obstacle is 1,20 $\mathrm{m}$. If the scooter is faster than $6 \mathrm{~km} / \mathrm{h}$ and if the ultrasonic distance sensor detects an obstacle in this area, the motor will change to idle run and the scooter will reduce speed. I.e. driving on a narrow path is restricted to electrical assistance not faster than $6 \mathrm{~km} / \mathrm{h}$.

To limit the electrical assistance maximum velocity, a control program was developed. A rough program execution as flow chart is shown in Fig. 5. After the initialization, the current velocity is determined. Afterwards, the state of the gas button and the state of the brake lever is read to recognize if the driver wants to speed up or if he wants to brake. The ultrasonic sensor then measures the distance to the closest obstacle in front of the scooter. 


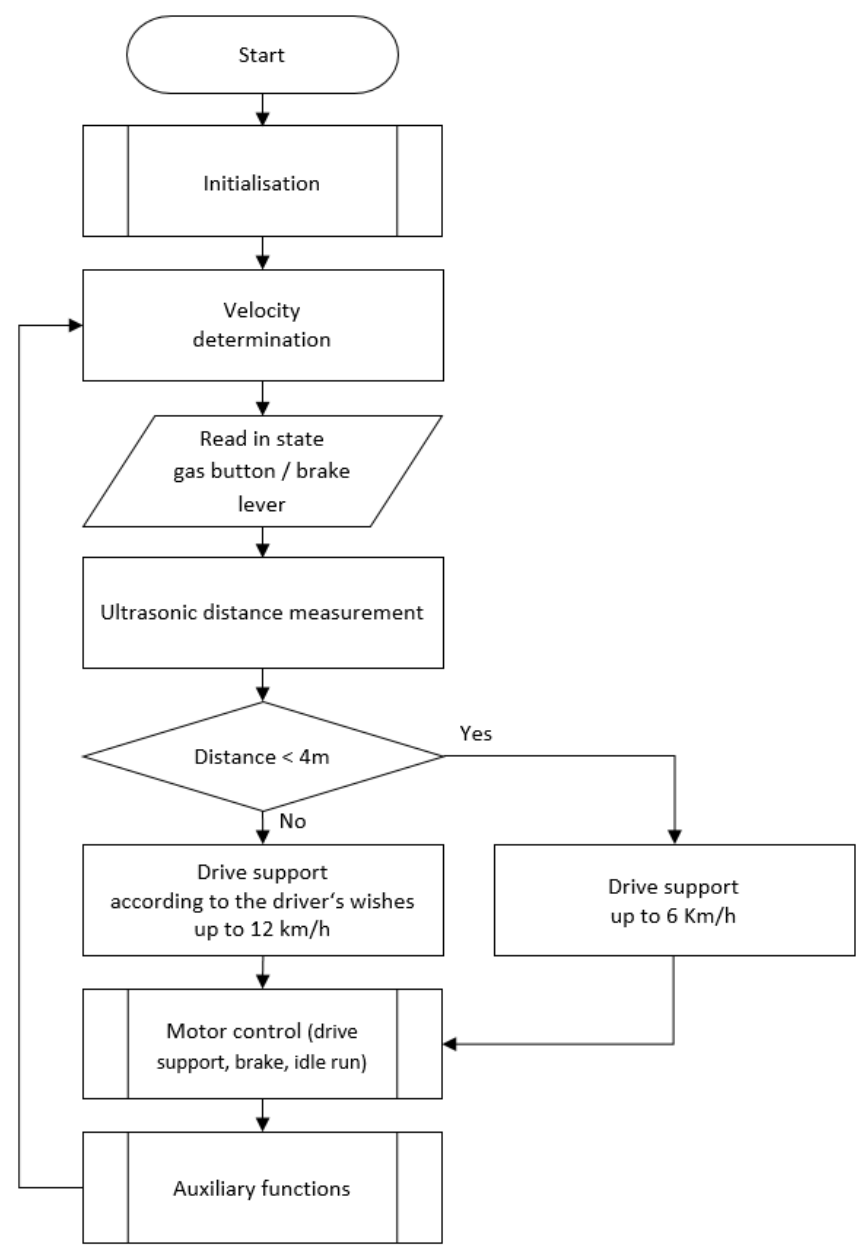

Figure 5: Flow chart of the program execution.

If the distance to the obstacle is less than $4 \mathrm{~m}$ the drive support only works up to $6 \mathrm{~km} / \mathrm{h}$. When the scooter is faster than $6 \mathrm{~km} / \mathrm{h}$ the motor changes to idle run and the scooter rolls without electrical assistance until the velocity drops under $6 \mathrm{~km} / \mathrm{h}$. The velocity of $6 \mathrm{~km} / \mathrm{h}$ is maintained until the sensor doesn't detect a person or an object closer than $4 \mathrm{~m}$. If there is no obstacle closer than $4 \mathrm{~m}$ the drive support is adapted to the driver's wishes up to $12 \mathrm{~km} / \mathrm{h}$. The current velocity is monitored constantly and controlled by a PI speed controller. Finally, the motor control manages the different operation points like drive support, brake and idle run. The program execution ends with the execution of auxiliary functions like an automatic switch-off after a given period of time as well as saving the actual mileage.

To proof the ASL system, the velocity, the distance to the closest obstacle and the motor power were recorded while driving parallel to a wall. During the first meter, the route is obstacle-free, then the driver reaches the wall and drives parallel to it as shown in Fig. 6.

Fig. 7 shows the scaled values of velocity (blue curve), power (yellow curve) and measured distance to an obstacle (red curve) according to the above-mentioned examination. 
The green curve illustrates the $4 \mathrm{~m}$ distance from the ultrasonic sensor to the obstacle. As already mentioned, the obstacle is given by a wall close to the sidewalk. At first, the scooter is accelerating up to its maximum speed. After 8 seconds, the distance to the wall gets smaller than $4 \mathrm{~m}$. At this moment, the power curve drops down delivering only a low torque from the motor. As a consequence, the velocity is decreasing.

When driving parallel to the wall the detected distance is smaller than $4 \mathrm{~m}$ in most cases, keeping the ASL activ. The lower setpoint velocity of $6 \mathrm{~km} / \mathrm{h}$ is reached after 12 seconds, enabling the scooter maintaining the lower set velocity until the end of the experiment. To maintain the velocity of $6 \mathrm{~km} / \mathrm{h}$ the motor power is increasing again in the last 6 seconds of the test. According to unsteady steering movements, as shown in the diagram, the sensor distance curve surpasses the $4 \mathrm{~m}$-distance line (green) twice between 8 and 12 seconds. This behavior is also visible in the short increase of the power curve. Due to the total vehicle inertia, this short power increase has no effect on the velocity. In summary, it is shown that the scooter with ASL removes power reliably when detecting an obstacle closer than $4 \mathrm{~m}$. Consequently, the electric scooter gets slower.

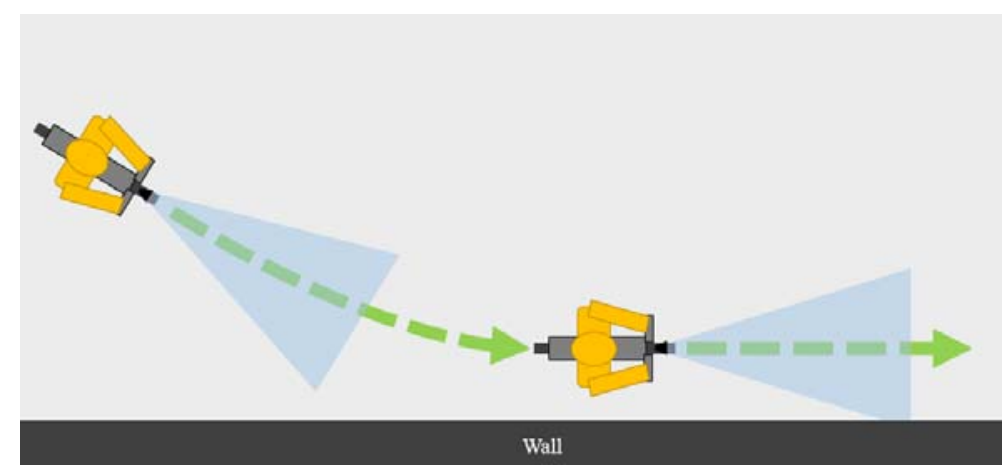

Figure 6: Examination of driving parallel to a wall.

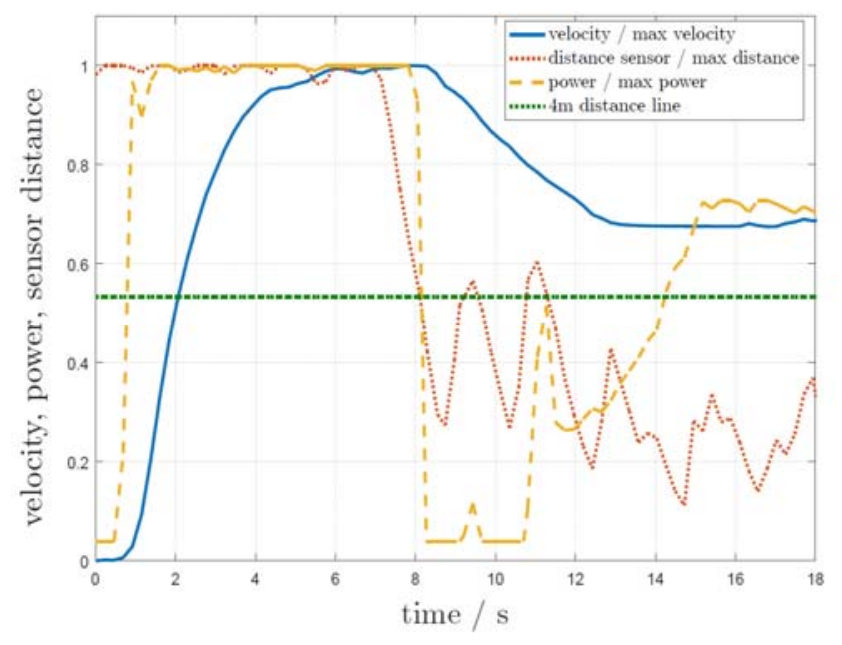

Figure 7: Scaled velocity, power and sensor distance to their respective maximum value vs time when driving close to a wall. 


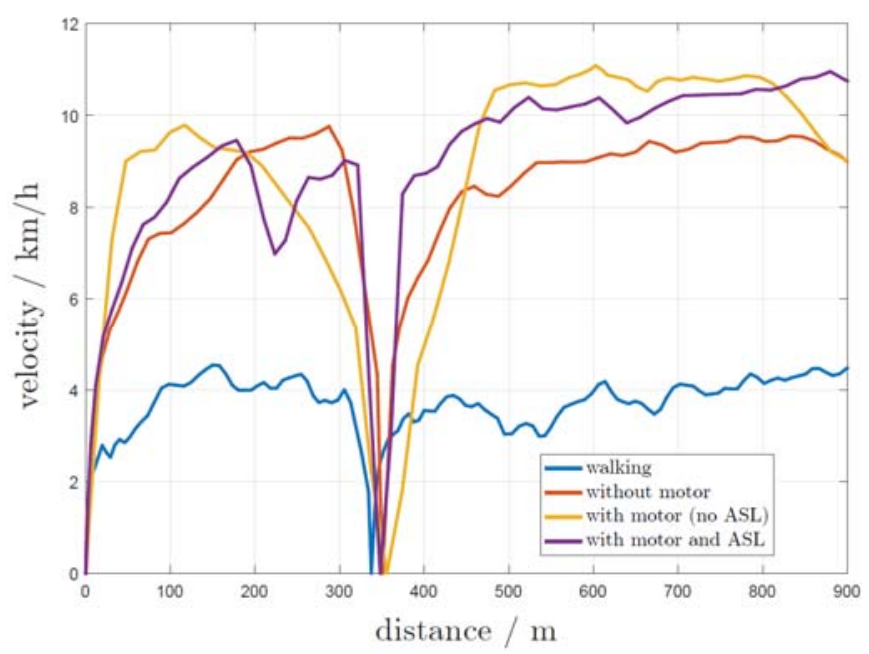

Figure 8: Measured velocity of different scooter configurations in comparison to walking.

Table 2: Comparison of different scooter velocities with pedestrian velocity.

\begin{tabular}{|l|c|c|}
\hline & $\begin{array}{c}\text { Average speed in } \mathrm{km} / \mathrm{h} \\
\text { (without standstill) }\end{array}$ & $\begin{array}{c}\text { Duration in min } \\
\text { (including standstill) }\end{array}$ \\
\hline Walking & 4 & 15 \\
\hline Without motor & 8 & 7 \\
\hline $\begin{array}{l}\text { With motor (no } \\
\text { ASL) }\end{array}$ & 10 & 6 \\
\hline $\begin{array}{l}\text { With motor and } \\
\text { ASL }\end{array}$ & 9 & 7 \\
\hline
\end{tabular}

The behaviour of the electric scooters velocity, when used in an everyday situation, is also of interest. Fig. 8 shows the velocity of different scooter configurations in comparison to the velocity of walking when passing a typical 'last mile' route. The route starts at the Hochschule Esslingen and ends at the train station of Esslingen. The distance of the route is $900 \mathrm{~m}$. In the diagram, a rapid velocity drop down at $350 \mathrm{~m}$ can be seen. The reason for this standstill is a pedestrian crossing to cross the carriageway. Leaving aside the standstill, the pedestrian has an average speed of less than $4 \mathrm{~km} / \mathrm{h}$ (blue curve) while the different scooter configurations are faster. The average speed of the unmotorized scooter (brown curve) is 8 $\mathrm{km} / \mathrm{h}$.

The scooter with electrical assistance and no ASL (yellow curve) is reaching the highest average velocity of $10 \mathrm{~km} / \mathrm{h}$. Finally, the scooter with driving support and ASL is reaching an average speed of $9 \mathrm{~km} / \mathrm{h}$ (purple curve). If the ultrasonic sensor detects an obstacle closer than $4 \mathrm{~m}$ and when the electric scooter is faster than $6 \mathrm{~km} / \mathrm{h}$ it doesn't accelerate. As indicated in Fig. 8, the purple curve shows an example for speed reduction after $220 \mathrm{~m}$ caused by a detected obstacle on or close to the pedestrian walk. Respecting the standstill, the scooter without driving support needs 7 minutes, the pedestrian 15 minutes and the scooter with driving support and ASL 7 minutes. The ASL-scooter only takes 1 minute longer than the electric scooter without ASL. Table 2 summarizes the average speeds and the duration of the 
pedestrian and the different scooters to the destination. Even in an everyday situation the electric scooter with ASL proves to response reliably to obstacles while being faster than an electric scooter with a maximum speed of $6 \mathrm{~km} / \mathrm{h}$.

\section{FLEET TEST RESULTS}

For demonstrating purposes of the fleet test, a start and destination point of a given route is chosen. The route is driven twice. The first time only by scooter and the second time partially by scooter and partially by bus. Therefore, two different routes have to be taken. The route starts close to the city centre of Esslingen and ends at a destination on a hill next to Esslingen. The route includes an altitude difference of around $100 \mathrm{~m}$ within $1,5 \mathrm{~km}$ length. Due to the great slope, the drive chain is stressed extremely. For this fleet test a scooter with electrical assistance but without ASL was used. In order to test the electric scooter under hard conditions the scooter is not kicked (no additional human power). Fig. 10 and Fig. 12 show the two different possibilities of driving the route.

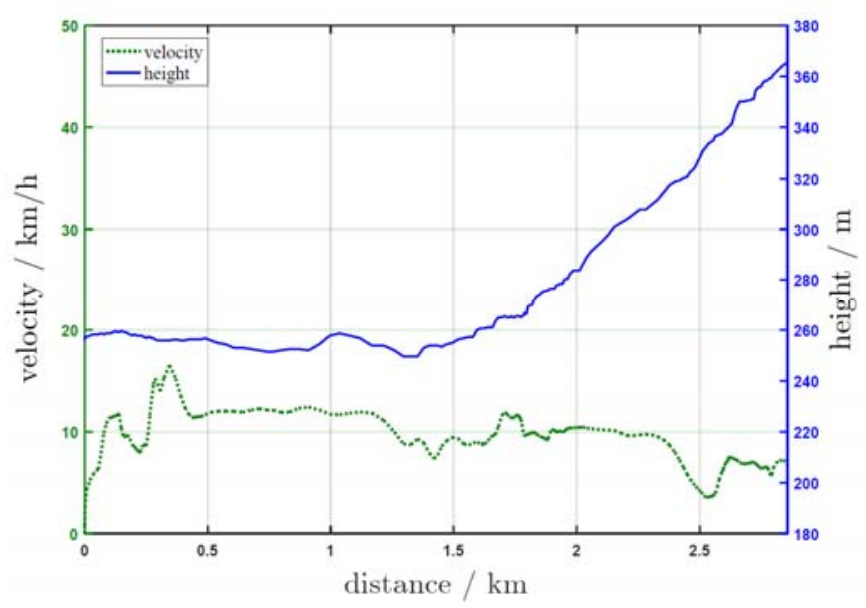

Figure 9: Scooter velocity and height vs. distance for an uphill route.

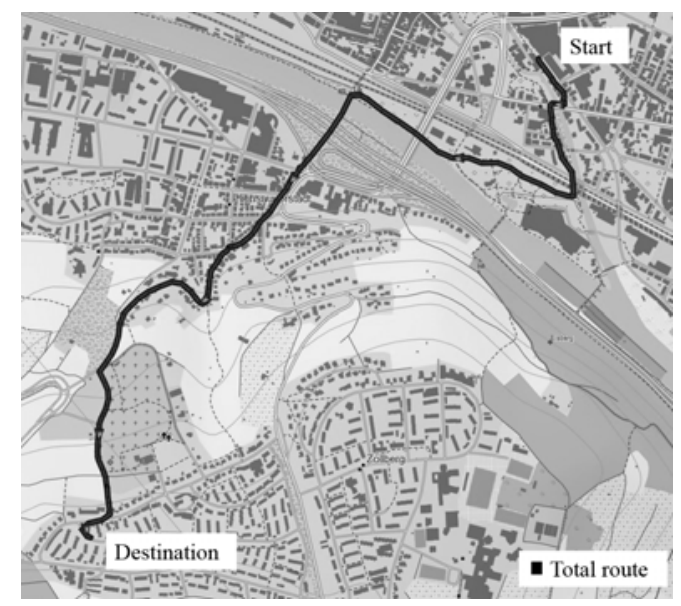

Figure 10: Total route driven only by electric scooter. 
The first possibility is to drive the whole route by electric scooter. The scooter velocity (green) and the altitude (blue) vs. distance are shown in Fig. 9. It can be seen, that the first part of the route up to $1.5 \mathrm{~km}$ is in a flat environment. In the second half, the route gets significantly steeper until the destination is reached. As illustrated in Fig. 9, the scooter covers a distance of $2.7 \mathrm{~km}$ when taking the most direct route. The fastest and most suitable route for driving with scooter is illustrated in Fig. 10. For driving this route only with electric scooter, it takes 19 minutes. In comparison, the pedestrian needs 40 minutes.

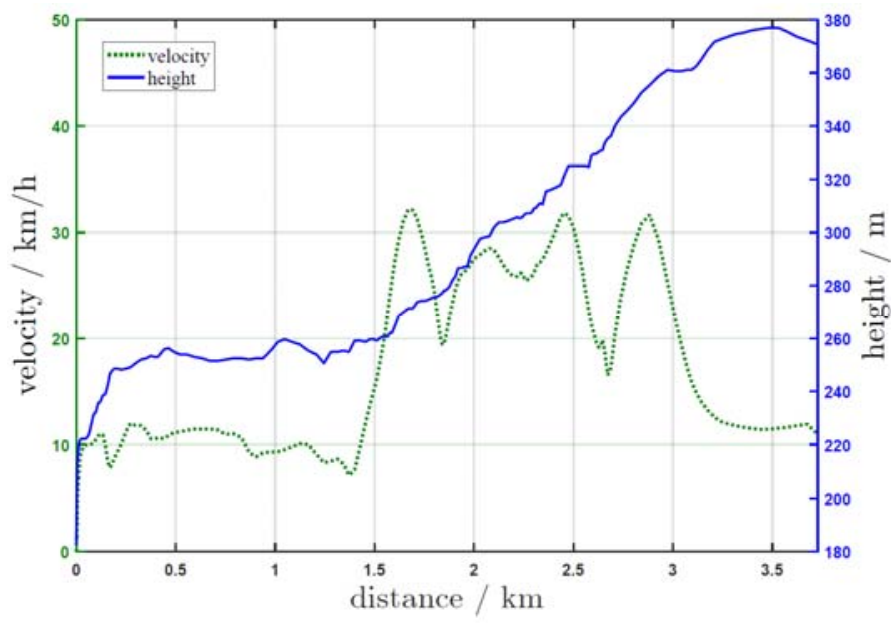

Figure 11: Last mile concept: electric scooter and bus velocity vs. distance and height vs. distance.

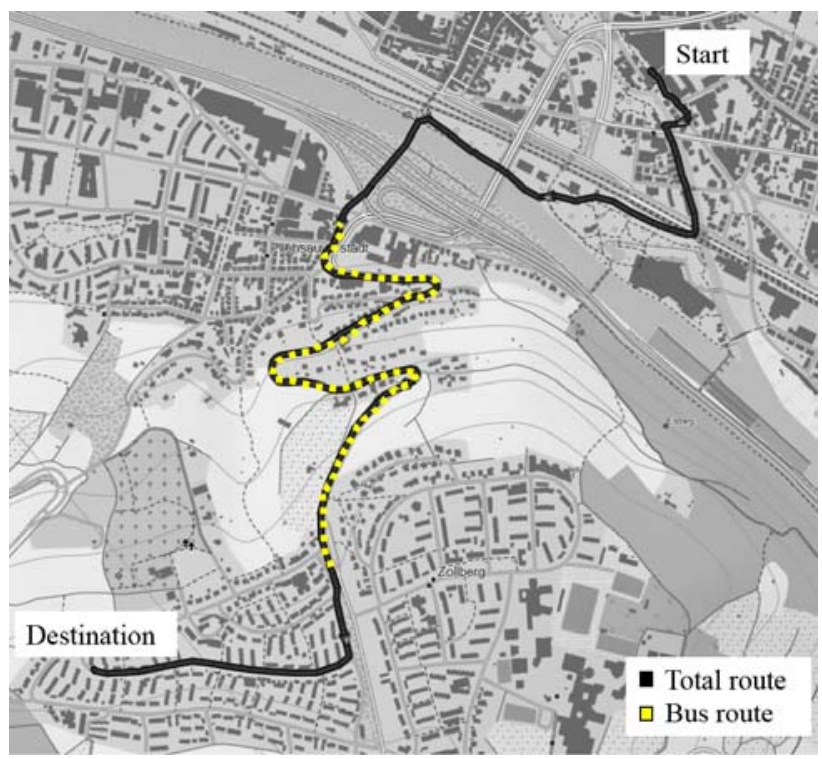

Figure 12: Total route (black) and route driven by bus (yellow). 
The second possibility is to split the route and drive partially by electric scooter and partially by bus. As seen in Fig. 11, the velocity (green) increases up to $30 \mathrm{~km} / \mathrm{h}$ on the bus segment (dotted yellow line in Fig. 12). The bus route is different to the direct path driven only by scooter. The alternative route with bus segment has a length of $3,7 \mathrm{~km}$ and takes 23 minutes, i.e. 4 minutes longer than required for the first alternative due to waiting times.

This exemplary fleet test shows that the electric scooter can be used for climbing great slops as well as following the 'last mile' concept when partially taking the bus. The evaluation of a fleet test with 24 scooters in Stuttgart ist part of the ongoing work. A larger fleet test with up to 50 scooters ist planned for spring 2017 after the MVI-BW has accepted the ASL extension.

\section{CONCLUSIONS}

Slow foldable E-ULV have proven to be a key element for future sustainable public traffic chains. The electrification can be realized by a light and inexpensive add-on kit that can be adapted for several folding scooters. The E-ULV have a significant potential to shift car-kilometers to the public transport if their operating velocity is in the range of unpowered scooters. The main obstacle for a legal applicable electric "last mile scooter" is the missing vehicle category on public walkways. The ultrasonic sensor based adaptive speed limitation in the ongoing fleet experiment will lead to the acceptance of electrified folding scooters on public walkway as "tolerated toys" by the traffic authorities.

\section{ACKNOWLEDGEMENTS}

This contribution had been worked out in the applied research project "Nachhaltig Mobil TrottiElec", funded by the Ministry of Traffic and Infrastructure Baden-Württemberg, Stuttgart. The authors thank for the support of TÜV SÜD in Munich/Pforzheim and the support of the industrial Partners Hudora GmbH, Remscheid, and Robert Bosch GmbH, Renningen.

\section{REFERENCES}

[1] Kagerbauer, M., Hilgert, T., Schroeder, O. \& Vortisch, P., Household travel survey of intermodal trips - Approach, challenges and comparison. Transportation research procedia, 11, pp. 330-339, Elsevier, 2015.

[2] Zirn, O. \& Rüther, M., Foldable Electrified Ultralight Vehicles as Key Component for Sustainable Traffic Chains. 5th International Energy and Sustainability Conference, IEEE Xplore DOI 10.1109/IESC.2016.7569483.

[3] Petits véhicules motorisés (SUIVI DU CEN/TC 354) AFNOR/S55T prEN16990, Online. http://www2.afnor.org, 2016.

[4] Zirn, O., Strobel, O. \& Norkauer, A., TrottiElec-ultraleichter E-Kickroller für geschlossene Wegeketten im urbanen Verkehr. AALE 2014, OTH Regensburg, 8./9.5.2014. 